\title{
(6) OPEN ACCESS \\ Management of established coronary artery disease in aircrew with previous myocardial infarction or revascularisation
}

\author{
Eddie D Davenport, ${ }^{1}$ Thomas Syburra, ${ }^{2}$ Gary Gray, ${ }^{3}$ Rienk Rienks, ${ }^{4}$ Dennis Bron, ${ }^{5}$ \\ Olivier Manen, ${ }^{6}$ Joanna d'Arcy, Norbert I Guettler, ${ }^{7}$ Edward D Nicol ${ }^{7}$
}

${ }^{1}$ Aeromedical Consult Service, United States Air Force School of Aerospace Medicine, WrightPAtterson AFB, Ohio, USA ${ }^{2}$ Cardiac Surgery Department, Luzerner Kantonsspital, Luzern, Switzerland

${ }^{3}$ Canadian Forces Environmental Medical Establishment, Toronto, Ontario, Canada

${ }^{4}$ Department of Cardiology, University Medical Center Utrecht and Central Military Hospital, Utrecht, The Netherlands

${ }^{5}$ Aeromedical Centre, Swiss Air Force, Zürich, Switzerland

${ }^{6}$ Aviation Medicine Department, AeMC, Percy Military Hospital,

Clamart, France

${ }^{7}$ Aviation Medicine Clinical Service, RAF Centre of Aviation Medicine, RAF Henlow, Bedfordshire, UK

${ }^{8}$ German Air Force Center for Aerospace Medicine, Fuerstenfeldbruck, Germany

\section{Correspondence to}

Dr Edward D Nicol, Aviation Medicine Clinical Service, RAF Centre of Aviation Medicine RAF Henlow, Bedfordshire, SG16 6DN; e.nicol@nhs.net

Received 17 March 2018 Revised 3 June 2018 Accepted 11 June 2018

\section{ABSTRACT}

This manuscript focuses on the broad aviation medicine considerations that are required to optimally manage aircrew with established coronary artery disease (CAD) without myocardial infarction (MI) or revascularisation (both pilots and non-pilot aviation professionals). It presents expert consensus opinion and associated recommendations and is part of a series of expert consensus documents covering all aspects of aviation cardiology.

Aircrew may present with MI (both ST elevation MI (STEMI) and non-ST elevation MI (NSTEMI)) as the initial presenting symptom of obstructive CAD requiring revascularisation. Management of these individuals should be conducted according to published guidelines, ideally with consultation between the cardiologist, surgeon and aviation medical examiner. Return to restricted flight duties is possible in the majority of aircrew; however, they must have normal cardiac function, acceptable residual disease burden and no residual ischaemia. They must also be treated with aggressive cardiac risk factor modification. Aircrew should be restricted to dual pilot operations in non-highperformance aircraft, with return to flying no sooner than 6 months after the event. At minimum, annual follow-up with routine non-invasive cardiac evaluation is recommended.

\section{INTRODUCTION}

When compared with the general population, aircrew are more likely to be found to have obstructive, flow-limiting, coronary artery disease (CAD) in the absence of significant symptoms. This is likely a result of the occupational periodic medical examinations (PME) that aircrew undergo that includes a thorough cardiovascular assessment. Revascularisation may be performed via percutaneous coronary intervention (PCI), coronary artery bypass grafting (CABG), or a hybrid combination, to reduce angina, resolve ischaemia, abort myocardial infarction (MI), and/or decrease mortality and prolong life.

When considering returning aircrew to flight duties following revascularisation, three factors are usually paramount; the type of revascularisation (CABG vs PCI vs hybrid); expected reoccurrence rates in the areas of revascularisation; and residual disease burden (including assessment of left ventricular (LV) ejection fraction and regional wall motion, scar burden, and viability). Decisions regarding revascularisation, including bystander disease, should be based on established clinical indications and not solely on aeromedical concerns. However, flight safety does require special consideration and in certain circumstances revascularisation may be considered outwith usual clinical indications, to mitigate specific occupational risk, after thorough discussion and consent with the aircrew.

The value of a multidisciplinary approach (between cardiologist, cardiovascular surgeon and aviation medical examiner (AME)/flight surgeon) cannot be over emphasised, nor can the importance of aggressive secondary modification of risk factors.

\section{PERCUTANEOUS CORONARY INTERVENTION}

In this paper, PCI refers to any catheter-based coronary artery revascularisation, including percutaneous transluminal coronary angioplasty (PTCA),
D) Check for updates

(c) Author(s) (or their employer(s)) 2018. Re-use permitted under CC BY-NC. No commercial re-use. See rights and permissions. Published by BMJ.

To cite: Davenport ED, Syburra T, Gray G, et al. Heart 2019;105:s31-s37.
Evidence-based cardiovascular risk assessment in aircrew poses significant challenges in the aviation environment as data to support decision making at the low level of tolerable risk in aviation are rarely available from the published literature. As a result, there are discrepancies between aviation authorities' recommendations in different countries, and even between licensing organisations within single countries. The North Atlantic Treaty Organization (NATO) HFM-251 Occupational Cardiology in Military Aircrew working group comprises full-time aviation medicine and aviation cardiology experts who advise both their military and civil aviation organisations including, but not limited to, the US Federal Aviation Authority (FAA), the UK Civil Aviation Authority (CAA), the European Aviation Safety Agency (EASA) and the US National Aeronautics Space Administration (NASA). The recommendations of this group are as a result of a 3 year working group that considered best clinical cardiovascular practice guidelines within the context of aviation medicine and risk principles. This work was conducted independently of existing national and trans-national regulators, both military and civilian, but considered all available policies, in an attempt to determine best evidence-based practice in this field. The recommendations presented in this document, and associated manuscripts, is based on expert consensus opinion of the NATO group. This body of work has been produced to develop the evidence base for military aviation cardiology and to continue to update the relevant civilian aviation cardiology advice following the 1998 European Cardiology Society aviation cardiology meeting. 
Table 1 Recommendations for percutaneous coronary intervention

\begin{tabular}{ll}
\hline Recommendations & \\
\hline $\begin{array}{l}\text { Bare metal stents and drug eluting stents are } \\
\text { acceptable for aircrew. }\end{array}$ & Strongly recommended \\
$\begin{array}{l}\text { Because of the high rate of early restenosis, non- } \\
\text { stent (plain old balloon) angioplasty (POBA) is not } \\
\text { recommended for aircrew. }\end{array}$ & Not recommended \\
$\begin{array}{l}\text { Fully bioresorbable stents/scaffolds are not } \\
\text { recommended for aircrew. }\end{array}$ & Not recommended \\
\hline
\end{tabular}

directional and rotational atherectomy, thrombectomy, laser guided procedures, and the deployment of coronary artery stents (either bare metal stents (BMS), or more commonly drug-eluting stents (DES)).

Non-stent (plain old balloon) angioplasty (POBA) has early restenosis rates as high as $30-35 \%$, which most often occurs within the first 2-3 months, with annual event rates of $2-4 \%$ per year, out to 5 years, and $5-7 \%$ per year after 5 years. ${ }^{1-3}$ This level of recurrence and disease progression is not compatible with maintenance of flying privileges.

Delayed endothelialisation and increased platelet aggregation (with increased late in-stent thrombosis) is a specific risk with DES. This is minimised with dual antiplatelet therapy (DAPT). Most recent PCI trials report annual major adverse cardiac event (MACE) rates of 1-2\% per year for successful and uncomplicated single or two-vessel disease, although importantly most stent failure occurs in the first 6 months. ${ }^{145}$ With a 6 month waiting period after revascularisation, and concomitant medical therapy, the risk is likely lower and thus it may be acceptable for aircrew, depending on their specific role, to return to flying duties, although with restrictions. Based on current data, bioresorbable polymer DES and standard DES appear to be comparable and are acceptable in aircrew ${ }^{6}$; however, fully bioresorbable stents/ scaffolds do not have the same favourable findings and are not recommended (table 1 ).

\section{CORONARY ARTERY BYPASS SURGERY}

To address the question of return to flight for commercial pilots, post-CABG, a dedicated sub-study of the CASS (Coronary Artery Surgery Study) Registry was used to select 2326 patients who had clinical and postoperative characteristics like those of commercial airline pilots. The probability of MACE over 5 years was $1.6 \%$ per year overall but decreased to $0.4 \%$ per year in those who had never smoked and had no history of hypertension. ${ }^{8}$ Historic data on CABG outcomes from within the civilian aeromedical community demonstrate death or MI rates of $<2 \%$ per year, with repeat revascularisation rates of $3-4 \%$ per year. ${ }^{9} 10$ However, more recent data suggest the contemporaneous MACE rate is closer to $1 \%$ per year. ${ }^{11}$ Additionally, aircrew populations often have a lower cardiovascular risk compared with the general clinical population. Therefore, for aircrew following CABG, with aggressive risk factor modification and close follow-up, restricted return to flight duties in

non-high-performance aircraft may be possible, depending on the risk threshold accepted by the individual aircrew's respective regulatory authority.

Selection of grafts for aircrew during CABG is an area of ongoing research and should follow the latest guidelines. Competitive flow and lack of haemodynamically significant stenosis in the native vessel adversely effects graft patency and assessment of fractional flow reserve (FFR) should be done during angiography for any lesion with $>50 \%$ stenosis to verify haemodynamic significance. Data support preferential use of arterial (internal mammary artery) grafts over venous grafts for all haemodynamically significant stenosis and strong consideration of bypass for moderate (51-70\%) left sided lesions, while clinical guidelines suggest that moderate right sided lesions may be left untouched and treated medically. ${ }^{12-15}$

No surgical evidence supports revascularisation of stenoses $\leq 50 \%$ (non-obstructive lesion) or 51-70\% (non-haemodynamically significant lesion). This is due to competitive flow that occurs when less than severe stenoses are grafted which negatively affects graft patency. ${ }^{16}$ High competitive flow induces a high oscillatory shear index (OSI); which is a quantification of the change in direction and magnitude of the wall shear stress. A high OSI is associated with endothelial dysfunction and atherogenesis, leading to graft failure and poor revascularisation outcome as well as repeat revascularisation. ${ }^{17}$ Saphenous vein grafts are less affected by competitive flow than arterial grafts, although arterial grafts are nowadays the preferred choice of conduit for the revascularisation of the left sided coronary artery lesions given the superior long-term patency rates. Radial artery grafts should not be used for stenoses that are less than critical $(<90 \%)$, as this conduit is the most sensitive to competitive flow. FFR measurement during angiography is of great assistance to the surgeon in supporting the choice of targets and conduits for revascularisation and thus should be considered in all aircrew with borderline stenoses to verify their haemodynamic significance.

Table 2 Recommendations for percutaneous coronary intervention (PCI) versus coronary artery bypass grafting (CABG)

\begin{tabular}{ll}
\hline Recommendations & \\
\hline $\begin{array}{l}\text { Published clinical guidelines rather than aeromedical } \\
\text { considerations should be the primary consideration }\end{array}$ & \\
for determining revascularisation with PCI or CABG. & \\
$\begin{array}{l}\text { A waiting period of at least } 6 \text { months after } \\
\text { revascularisation is required before assessing aircrew }\end{array}$ & Strongly recommended \\
for return to flight status. & \\
$\begin{array}{l}\text { For aircrew being considered for proximal left } \\
\text { anterior descending coronary artery (LAD) }\end{array}$ & Recommended \\
revascularisation, proactive consideration should be & \\
given to the left internal mammary artery (LIMA) & \\
graft over PCI, given long term benefit. & \\
Revascularisation may be considered for & Consider \\
occupational risk modification outside clinical \\
indications after thorough discussion and consent \\
with the aircrew.
\end{tabular}

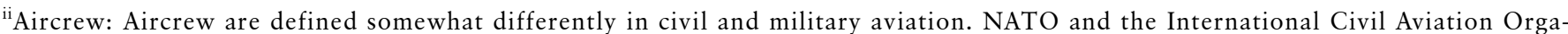
nization (ICAO) delegates the definition of aircrew to national authorities. In the civilian sector aircrew are often categorised as flight crew (pilots)/technical crew members and cabin crew, with separate regulation for air traffic controllers (ATCO). The military define aircrew more broadly as "persons having duties concerned with the flying or operation of the air system, or with passengers or cargo when in flight". From a risk perspective, professional (commercial) pilots have a higher attributable risk than private pilots and non-pilot aircrew. Controllers are considered to have an attributable risk equivalent to professional pilots. From a cardiovascular perspective, aircrew whose flying role includes repetitive exposure to high acceleration forces (Gz) comprise a subgroup who, due to the unique physiological stressors of this flight environment, often require specific aeromedical recommendations. A more detailed description of aircrew is available in table 1 - of the accompanying introductory paper on aviation cardiology (Nicol ED, et al. Heart 2018;105:s3-s8. doi:10.1136/heartjnl-2018-313019).
} 


\section{PCI VERSUS CABG}

Over the past 30 years there have been many randomised controlled trials and meta-analyses regarding PCI versus CABG that have shown no difference in death or MI in most non-diabetic patients. ${ }^{111218}$ However, MACE rates consistently favour CABG over PCI with 5 year event rates approximately 4\% higher in those with PCI versus CABG. ${ }^{1118}$ Revascularisation consistently drives the primary endpoints in all studies, and neither death nor MI have been demonstrated to be significantly different between PCI and CABG. One exception to this is the left internal mammary artery (LIMA) to left anterior descending coronary artery (LAD) revascularisation for any disease involving the left main and/or proximal LAD; given graft durability and likely a long-term mortality benefit over PCI in all patients, CABG is therefore recommended in the most recent guidelines. ${ }^{19}{ }^{20}$ In all cases, calculation of a SYNTAX score and heart team approach with careful discussion between the general cardiologist, interventional cardiologist and cardiothoracic surgeon is paramount.

There are data to support favourable outcomes with hybrid revascularisation (combining PCI and CABG) and this approach can be utilised as indicated in aircrew. ${ }^{21} 22$ Overall, published clinical guidelines should be followed for aircrew, without regard to occupational flight status, which currently favours CABG for multivessel disease (three or more coronary arteries, or two if including proximal LAD or dominant left circumflex (LCx)) and left main stem disease. ${ }^{19}$ Repeat revascularisation following PCI or CABG can be as high as 5-9\%, while MI and mortality rates are consistently $<2 \%$ per year. Kaplan-Meier data consistently show an early spike in complication rates for both PCI and CABG, with a more linear curve after 6 months ${ }^{11}$; therefore a waiting period of no less than 6 months following revascularisation is required before consideration of resuming aircrew duties (table 2).

Event rates after CABG or PCI in military aircrew may be lower than in the general population. In a retrospective review of United States Air Force (USAF) aircrew with no prior cardiac events that underwent coronary artery revascularisation with PCI or CABG, there were no cardiac deaths within 5 years and cumulative cardiac event rates (MACE) at 1 and 5 years were $1.0 \%$ and $3.6 \%$, respectively. ${ }^{23}$ All aircrew requiring revascularisation were identified during annual re-evaluation (as described be at least partially attributed to the younger age of military pilots, as published data in young patients ( $<40$ years of age) demonstrate 10 year event-free survival rates over $90 \%$, even in the pre-statin era. ${ }^{24-26}$ These high success rates included patients revascularised with either PCI or CABG, regardless of presenting symptoms such as angina, ischaemia and/or MI.

Table 3 Recommendations for follow-up after simple revascularisation

Recommendations

\begin{tabular}{ll}
\hline $\begin{array}{l}\text { Aircrew who have undergone a revascularisation } \\
\text { procedure should undergo repeat angiography and/or } \\
\text { functional ischaemia assessment no earlier than } 6 \text { months } \\
\text { after the procedure as part of the assessment of return to } \\
\text { aircrew duties. }\end{array}$ & $\begin{array}{l}\text { Strongly } \\
\text { recommended }\end{array}$ \\
$\begin{array}{l}\text { Aircrew who have undergone revascularisation should } \\
\text { have annual follow-up with non-invasive testing. }\end{array}$ & $\begin{array}{l}\text { Strongly } \\
\text { recommended }\end{array}$ \\
$\begin{array}{l}\text { Aircrew who have been returned to flight duties after } \\
\text { revascularisation or myocardial infarction should be } \\
\text { considered for repeat angiography (invasive coronary } \\
\text { angiography or coronary computed tomography }\end{array}$ & Consider \\
angiography) every 5years to remain on aircrew duties. & \\
\hline
\end{tabular}
below), not by symptomatic re-presentation. These results may

\section{FOLLOW-UP AFTER SIMPLE REVASCULARISATION}

Not uncommonly, aircrew will have a single high-grade stenosis in the setting of angina, MI and/or ischaemia, with no other angiographic evidence of CAD. The culprit stenosis is treated with revascularisation, such as DES, usually with excellent results. With no appreciable so-called 'bystander' disease, and a widely patent, stented artery, the important aeromedical question is that of risk for a future cardiovascular event. Aircrew will often have been informed-and feel as if-their CAD has been 'cured', despite revascularisation being a palliative procedure. However, in the aviation medicine setting, it is imperative to remember revascularisation has been used to mitigate potentially life-threatening CAD which is an end product of a complex metabolic, anatomic, immunologic and genetic disease process. Consequently, aircrew with revascularisation retain an increased lifetime risk of recurrent obstructive CAD. Aircrew who have undergone any form of revascularisation must undergo regular (at least annual) follow-up with non-invasive testing.

In many countries angiography is required in all military aircrew at 6-12 months, before return to flight status, and again at periodic (often 5 year) intervals while undertaking flying duties, regardless of non-invasive testing results. In a small USAF cohort of 76 asymptomatic aircrew with prior revascularisation and negative non-invasive studies, repeat angiography at 6 months, 3 years and 5 years demonstrated progression to severe disease in seven aircrew (9\%) at 6 months with no additional cases of significant progression at 3 years. Unfortunately, there was progression to severe CAD in a further nine $(12 \%)$ aircrew at 5 years; three of these underwent repeat revascularisation with the other six permanently disqualified from flying duties. We therefore recommend repeat angiography (coronary computed tomography angiography (CCTA) or invasive coronary angiography (ICA)) and functional ischaemia testing be done before return to flight status to ensure patency of the culprit vessel and grafts if present, as well as to evaluate residual disease burden (in non-revascularised vessels). Angiography should be done no earlier than 6 months after revascularisation then reconsidered at 5 year intervals if remaining on active flying duty (table 3 ). Secondary prevention with aggressive risk factor modification is mandated as discussed later in this article.

\section{Chronic total occlusions}

Chronic total occlusion (CTO) refers to a coronary artery with either no flow, or flow that does not reach the end vessel when assessed with ICA. CTO has been reported in 15-30\% of patients referred for ICA. Mortality rates for non-revascularised and revascularised CTO are consistently around 3\% per year. ${ }^{27}$ Return to flight duties in the setting of non-revascularised CTO is not recommended (table 4). Return to flight may be permitted in revascularised CTO in exceptional circumstances, in asymptomatic non-pilot aircrew with good functional status, no evidence of infarct/scar or ischaemia, normal LV function, and optimal secondary risk factor modification.

Table 4 Recommendations for chronic total occlusion (СТО)

\section{Recommendations}

\begin{tabular}{l|l}
\hline $\begin{array}{l}\text { In exceptional circumstances, non-pilot aircrew that have } \\
\text { undergone revascularisation of CTO may be considered for } \\
\text { return to restricted flight duties. }\end{array}$ & Consider \\
$\begin{array}{l}\text { Aircrew with CTO with or without revascularisation are not } \\
\text { recommended to return to flight duties. }\end{array}$ & $\begin{array}{l}\text { Not } \\
\text { recommended }\end{array}$ \\
\hline
\end{tabular}

In exceptional circumstances, non-pilot aircrew that have undergone revascularisation of CTO may be considered for Aircrew with CTO with or without revascularisation are not recommended to return to flight duties. 


\begin{tabular}{ll}
\hline Table 5 Recommendations for myocardial infarction (MI) \\
\hline Recommendations & \\
\hline $\begin{array}{l}\text { Cardiology specialist consultation is strongly recommended for } \\
\text { all aircrew with suspected MI before a return to flight/control }\end{array}$ & $\begin{array}{l}\text { Strongly } \\
\text { recommended }\end{array}$ \\
duties. & \\
Cardiac MRI is recommended in all aircrew where there is & $\begin{array}{l}\text { Strongly } \\
\text { recommended }\end{array}$ \\
diagnostic uncertainty of the diagnosis of MI. & Consider \\
Aircrew with a history of MI may be considered for a return & \\
to operational duties. Pilots require restriction to non-high & \\
performance aircraft with another pilot qualified on type. & \\
Criteria include minimal scar burden with normal global left & \\
ventricular function, no evidence of ischaemia or arrhythmia, \\
acceptably low residual coronary artery disease burden, \\
and normal cardiopulmonary function off all antianginal \\
medications. \\
$\begin{array}{l}\text { Aircrew with a history of MI with any evidence of heart failure, } \\
\text { ongoing tobacco use or diabetes should not be returned to }\end{array}$ & Not \\
flight duties. & \\
\hline
\end{tabular}

\section{Myocardial infarction in aircrew}

Cardiology specialist consultation is strongly recommended to confirm any diagnosis of $\mathrm{MI}$ in aircrew given the occupational implications. In aircrew it is essential that the diagnosis of MI is properly confirmed, especially in cases where the luminal findings on angiography are equivocal. Acute myocarditis may cause clinical, biochemical and ECG findings similar to MI and needs to be actively excluded in these cases. In myocarditis the coronary arteries may be normal or demonstrate
CAD that is unrelated to the event. It is essential for aircrew that these conditions are, as far as possible, delineated, as the occupational ramifications of each condition are significantly different. The gold standard for evaluation of myocarditis is cardiac MRI (CMR); the different pattern of cardiac scar in MI and myocarditis can be readily determined by late gadolinium enhancement uptake on CMR, and should be strongly considered in all aircrew with a history of chest pain where the diagnosis of $\mathrm{MI} /$ myocarditis is uncertain.

In addition to scar assessment, contrast-enhanced CMR can also characterise myocardial and microvascular injury and can provide additional detail on myocardial function and cardiac remodelling, and provide predictive value and prognosis for medium to longterm LV function. ${ }^{28} \mathrm{CMR}$ may also be useful for risk stratification in individuals who have had an MI, allowing assessment of the presence/absence of scar tissue, although no data exist that reliably quantifies scar burden with arrhythmia risk.

Prior MI increases the event rate for all significant CAD groups, with or without revascularisation. Short term (30 day) mortality for ST elevation MI (STEMI) and non-ST elevation MI (NSTEMI) is 2-5\% irrespective of type of reperfusion (fibrinolysis or urgent revascularisation). ${ }^{29}{ }^{30}$ Long-term mortality rates after MI are also consistently 2-5\% per year, with the highest mortality rates in NSTEMI patients (up to $8 \%$ ) and lowest in STEMI patients (as low as 2\%). $.^{20} 31-34$ Over 15 years mortality rates following MI have improved to approximately $2 \%$ per year; however, this increases dramatically to over $45 \%$ in those with heart failure symptoms or tobacco use, up to $65 \%$ in those with diabetes, and $>80 \%$ in

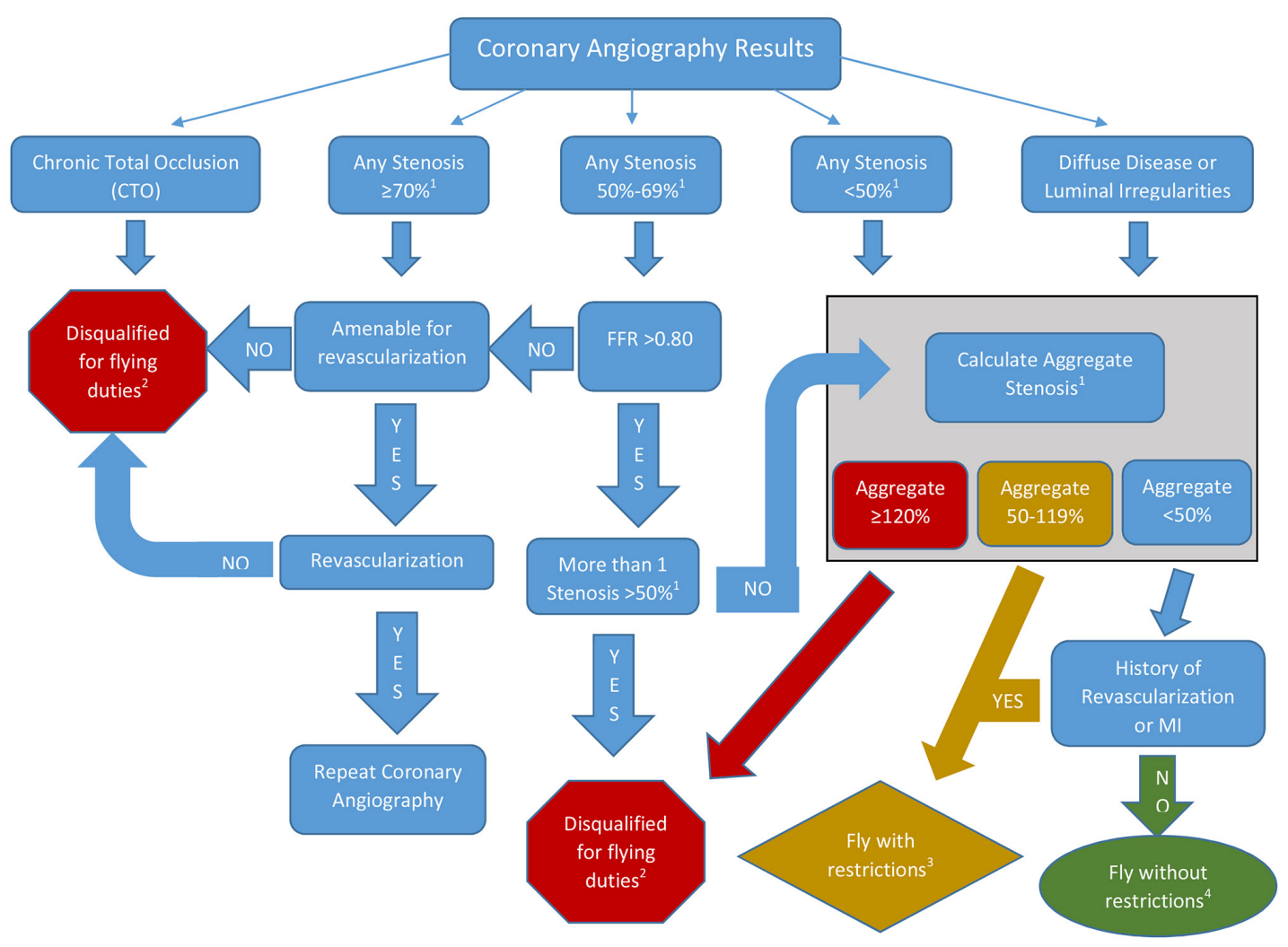

Figure 1 Aeromedical disposition recommendations based on coronary angiographic findings. 'Luminal diameter stenosis based on angiography. ${ }^{2}$ Return to non-pilot aircrew duties may be considered after careful risk assessment and risk mitigation if aggregate stenosis otherwise $<120 \%$. ${ }^{3}$ Restrictions include non-single seat and non-high performance aircraft. ${ }^{4}$ Aircrew with $30-50 \%$ stenosis may be restricted to non-high performance flight depending on local civilian and/or military regulations. Note: The recommended dispositions are an agency decision and may be modulated by associated coronary risk factor modification. FFR, fractional flow reserve; MI, myocardial infarction. 
those with an ejection fraction $<30 \% .{ }^{35}$ Aircrew with any signs of heart failure, tobacco use or diabetes, in addition to $\mathrm{CAD}$, are not recommended to return to flight duties (table 5).

While the overall mortality rates following MI would breach the usual ' $1 \%$ rule' in aircrew (referring to over 1\% risk of sudden incapacitation), the short and long-term mortality data are much improved in younger patients. Mortality rates in patients $<50$ years old are approximately $1 \%$ at 6 months, $3 \%$ at 4 years, and $6 \%$ at 5 years. ${ }^{36-39} \mathrm{~A}$ small study of USAF aircrew followed over 5 years post-MI demonstrated no cardiac deaths and no recurrent MI. Annual rates of revascularisation were 4\% in the first year, $2.3 \%$ at 2 years and $2.4 \%$ at 5 years; no aircrew presented with a recurrence of symptoms, and all revascularisations were because of abnormalities detected on scheduled annual testing. ${ }^{1}$ With newer generation stents, newer surgical techniques and more aggressive risk factor modification, the risk of sudden incapacitation likely falls below $1 \%$ per year, allowing consideration for return to limited flight duties for most aircrew.

Based on the above data, aircrew with a history of MI may be considered for return to operational duties. Pilots require restriction to non-high performance aircraft with another qualified pilot. Other aircrew require a detailed risk assessment related to their particular operational duties. Criteria for return to duties include minimal scar burden with normal global LV function, no evidence of ischaemia or arrhythmia, acceptably low residual CAD burden, and normal cardiopulmonary function off all antianginal medications. The final determination with regards to return to flying duties will also depend on the risk threshold accepted by the individual aircrew's respective regulatory authority.

\section{Residual disease after revascularisation}

In otherwise healthy aircrew, MI is not uncommonly the result of atherosclerotic plaque rupture of a single 'culprit' coronary artery lesion. Culprit vessel revascularisation in the acute setting decreases recurrent MACE, including mortality. ${ }^{40}$ However, controversy remains with regards to revascularisation of other, non-culprit artery, obstructive CAD. Current European Society of Cardiology (ESC) and American College of Cardiology/American Heart Association (ACC/AHA) guidelines recommend only infarct artery revascularisation unless there is cardiogenic shock in the presence of multiple critical stenoses, although there is evidence that those with multivessel CAD do have higher 30 day mortality rates. ${ }^{41}$ More recently, two large studies have shown significant decreases in MACE with complete revascularisation, including non-culprit lesions, as early as 30 days after revascularisation, with no difference in stroke, bleeding or nephropathy. ${ }^{42} 43$

Whether done at time of event, or staged (PCI of culprit vessel, followed by repeat PCI or CABG non- culprit lesions later), it is imperative that all aircrew have no residual haemodynamically significant disease. Non-revascularized CAD burden, including aggregate stenosis, ${ }^{44}$ can then be calculated on non-obstructive disease to determine risk. All aircrew with a prior MI and/or revascularisation should be risk assessed, and if within acceptable risk limits, can be considered for limited aircrew roles (ie, non-high-performance airframes), and for pilots, limited to dual pilot operations, with another suitably qualified pilot on that aircraft type, even when residual disease is minimal. All aircrew must also meet secondary risk factor recommendation goals for return to flight duties (table 6). Figure 1 summarises the occupational disposition of pilot aircrew based on angiographic findings.
Table 6 Recommendations for residual disease after revascularisation

\section{Recommendations}

For return to flight duties, aircrew with revascularisation should have no residual haemodynamically significant disease.

Non-revascularised coronary artery disease burden, to include aggregate stenosis, should be calculated in nonobstructive disease to determine risk.

All aircrew with myocardial infarction and/or revascularisation should be limited to non-high performance recommended airframes and for pilots, limited to dual pilot operations.

All aircrew must meet secondary risk factor recommendation Highly goals for return to flight duties. recommended

\section{Secondary prevention and follow-up}

Secondary prevention guidelines have been published by the ACC, ${ }^{45} \mathrm{AHA}^{46}$ and $\mathrm{ESC}^{47}$ and are summarised in table 7. Consensus between these guidelines for those with documented CAD include the use of aspirin and statins, aggressive blood pressure control, smoking cessation, regular exercise and weight control through dietary modification.

\section{Table 7 Recommendations for secondary prevention}

\begin{tabular}{l} 
Recommendations \\
$\begin{array}{l}\text { Statin therapy (or equivalent if intolerant of statins) should be } \\
\text { prescribed for all aircrew with confirmed coronary artery disease }\end{array}$ \\
$\begin{array}{l}\text { regardless of baseline low-density lipoprotein cholesterol to } \\
\text { decrease myocardial infarction and stroke risk. }\end{array}$ \\
$\begin{array}{ll}\text { Abstinence of tobacco use is mandatory for return to flight/ } & \text { Highly } \\
\text { control duties. } & \text { recommended }\end{array}$ \\
\hline
\end{tabular}

Statin therapy (or equivalent if statin not tolerated) should be prescribed for all aircrew with confirmed CAD regardless of baseline low-density lipoprotein cholesterol (LDL-C) to decrease $\mathrm{MI}$ and stroke risk. Aspirin should be continued indefinitely in all aircrew with CAD, while post-PCI, DAPT is indicated for at least 12 months. Hypertension should be aggressively managed, at least to $<140 / 90 \mathrm{~mm} \mathrm{Hg}$, and ideally to $120 / 80 \mathrm{~mm} \mathrm{Hg}$. ACE inhibitor or angiotensin II receptor blocker (ARB) as well as $\beta$-blocker therapy is recommended in all acute coronary syndromes (ACS) for at least 1 year after any event, and ideally out to 3 years if tolerated.

All aircrew with CAD must cease smoking. Tobacco use after revascularisation confers up to $40 \%$ risk of death, MI or repeat revascularisation. Abstinence of tobacco use is mandatory for return to aircrew duties (table 8). Moderate intensity aerobic activity for 30-60 min at least 5 days per week is recommended for all aircrew (after completion of cardiac rehabilitation if MI or revascularisation) and may reduce all-cause mortality by as much as $25 \%$. Maintenance of normal body mass index is recommended. Although not yet studied in aircrew, emerging data suggest the use of monoclonal antibodies that inhibit proprotein convertase subtilisin-kexin type 9 (PCSK9 inhibitors) may be useful and could be considered in aircrew in the future if appropriate safety data support this. ${ }^{48}$

\section{Follow-up}

While most major society guidelines argue against routine non-invasive cardiac evaluations in asymptomatic patients even with known $\mathrm{CAD}$, these guidelines do not take into account high 
Table 8 Merged secondary prevention guideline recommendations from the American Heart Association, American College of Cardiology and European Society of Cardiology

\begin{tabular}{llll}
\hline Secondary prevention & Evidence* $^{*}$ & Risk reduction & Referencest \\
\hline Statin therapy & Medical therapy & & \\
Aspirin therapy & Strong & $10-30 \%$ & 1,2 \\
\hline Blood pressure control & Medium & $20-25 \%$ & 1,2 \\
& $\begin{array}{l}\text { Strong } \\
\text { Lifestyle therapy }\end{array}$ & $20 \%$ & 1,2 \\
Tobacco cessation & Strong & $30-40 \%$ & 2 \\
\hline Diet control/weight loss & Medium & $20-30 \%$ & 2 \\
Physical activity & Medium & $20-30 \%$ & 1 \\
\hline Moderate alcohol & Weak & $17-30 \%$ & 1 \\
\hline Combined total risk reduction & $\mathbf{1 9 - 4 7 \%}$ & $\mathbf{1 , 2}$ \\
\hline
\end{tabular}

*Level of evidence: Strong=multiple randomised clinical trials or metaanalyses; Medium=single randomised or large non-randomised trials;

Weak=retrospective studies, registry data, or small studies and/or consensus of expert opinion.

tReferences are American College of Cardiology/American Heart Association (ACC/ AHA) and European Society of Cardiology (ESC) guidelines for stable coronary artery disease.

Reference 1: Fihn S, Gardin J, Abrams J, et al. 2012 ACCF/AHA/AATS/PCNA/

SCAI/STS Guideline for the diagnosis and management of patients with stable ischaemic heart disease. J Am Coll Cardiol 2012;60:e44-164.

Reference 2: Montalescot G, Sechtem U, Achenbach S, et al. 2013 ESC Guidelines on the management of stable coronary artery disease. Eur Heart J 2013;34:2949-3003.

risk occupations such as those performed by aircrew where flight safety is paramount. Initial follow-up of aircrew for return to flight status should occur no sooner than 6 months after MI and/ or revascularisation to ensure acceptable flight safety risk. After return to operational duties, aircrew should, at minimum, have an annual follow-up with their primary care provider, AME and cardiologist.

Although there are few data regarding the evaluation of asymptomatic patients post revascularisation, functional and physiologic testing has been shown to be highly predictive of future events. Even at 12 years of follow-up, those with normal stress testing demonstrate an annual mortality rate of approximately $0.9 \%{ }^{49}$ Determination of ischaemia is significantly higher with non-invasive imaging ( $85 \%$ sensitivity) compared with exercise stress testing (ExECG) alone (45\% sensitivity) and non-invasive functional imaging assesses the extent of ischaemia and vascular territory. ${ }^{50}$

All functional imaging modalities are acceptable in aircrew; both single photon emission CT (SPECT) nuclear imaging and stress echocardiography are acceptable forms of imaging with a negative predictive value of over $98 \%$ over 36 months, ${ }^{49}{ }^{51}$ while positron emission tomography (PET) has been shown to have increased sensitivity and specificity, with improved spatial resolution, when compared with SPECT and stress echo imaging. Stress CMR affords the highest spatial resolution, less soft tissue artefact, and provides anatomic and functional data without ionising radiation.

ExECG alone is not recommended as a sole investigation of ischaemia in aircrew (table 9); however, it is still of value when assessing cardiopulmonary functional status as a good functional capacity has consistently been shown to predict a lower longterm mortality rate. Exercise stress is preferred over chemical stress if possible. However, if imaging modalities do not allow exercise, then annual ExECG should also be considered for assessment of cardiopulmonary functional status. Other tests that should be considered annually, given the risk of adverse
Table 9 Recommendations for follow-up

\begin{tabular}{|c|c|}
\hline Recommendations & \\
\hline $\begin{array}{l}\text { Initial follow-up of aircrew for return to flight status should } \\
\text { occur no sooner than } 6 \text { months after myocardial infarction (MI) } \\
\text { and/or revascularisation to ensure acceptable flight safety risk. }\end{array}$ & $\begin{array}{l}\text { Highly } \\
\text { recommended }\end{array}$ \\
\hline $\begin{array}{l}\text { After return to flight, aircrew should at minimum have } \\
\text { an annual follow-up with their primary care provider, aviation } \\
\text { medical examiner and cardiologist. }\end{array}$ & $\begin{array}{l}\text { Highly } \\
\text { recommended }\end{array}$ \\
\hline $\begin{array}{l}\text { Annual review should include an ECG, resting echocardiogram } \\
\text { and } 24 \text { hour Holter monitor. }\end{array}$ & Consider \\
\hline $\begin{array}{l}\text { Exercise stress testing is not recommended as a sole } \\
\text { investigation to determine ischaemia in the assessment of } \\
\text { aircrew post-MI/revascularisation. }\end{array}$ & Not recomm \\
\hline
\end{tabular}

cardiac remodelling, include an ECG, resting echocardiogram, and 24 hour Holter monitor to evaluate for rest ischaemia, structural changes and/or arrhythmia. This is especially true in military aviation; however, it is less commonly done in the civilian sector. Secondary prevention must remain optimal for all aircrew including psychological aspects.

\section{CONCLUSION/SUMMARY}

All aircrew with coronary artery revascularisation and/or MI have an increased risk of death, myocardial infarction, revascularisation and possibly stroke. However, modern revascularisation techniques, advanced medical therapy and adherence to lifestyle changes can significantly decrease event rates. Depending on the underlying pathology, intervention and acceptable post-revascularisation investigations (ie, preserved LV function, no or minimal scar burden, no evidence of ischaemia, acceptable residual CAD burden), return to operational aircrew duties may be considered based on a detailed risk assessment. The predicted event rates require that pilots be restricted to dual pilot operations in non-high performance aircraft. As with all clinical decision-making in aircrew, the choice of revascularisation should be based on published guidelines. Outside the acute setting, consideration should be given to total plaque burden (aggregate stenosis) and the most appropriate strategy for treating multivessel or multi-lesion CAD (online supplementary table 10).

Contributors All authors contributed to the design and revision of this manuscript. Funding Produced with support from NATO CSO and HFM-251 Partner Nations. Competing interests None declared.

Patient consent Not required.

Provenance and peer review Commissioned; externally peer reviewed.

Data sharing statement There is no additional unpublished data to share.

Open access This is an open access article distributed in accordance with the Creative Commons Attribution Non Commercial (CC BY-NC 4.0) license, which permits others to distribute, remix, adapt, build upon this work non-commercially, and license their derivative works on different terms, provided the original work is properly cited, appropriate credit is given, any changes made indicated, and the use is non-commercial. See: http://creativecommons.org/licenses/by-nc/4.0/.

\section{REFERENCES}

1 Kruyer WB, Davenport ED. Clinical aviation medicine. New York: Castle Connolly Graduate Medical Publishing LTD, 2013:33-5.

2 Moorman DL, Kruyer WB, Jackson WG. Percutaneous transluminal coronary angioplasty (PTCA): long-term outcome and aeromedical implications. Aviat Space Environ Med 1996;67:990-6.

3 Hueb WA, Soares PRN, Oliveira SA, et al. Five-year follow-up of Medicine, Angioplasty, or Surgery Study (MASS). Circulation 1999;100:107-13. 
4 Horst B, Rihal CS, Holmes DR, et al. Comparison of drug-eluting and bare-metal stents for stable coronary artery disease. JACC Cardiovasc Interv 2009;2:321-8.

5 Mauri L, Kereiakes DJ, Yeh RW, et al. Twelve or 30 months of dual antiplatelet therapy after drug-eluting stents. N Engl J Med 2014;371:2155-66.

6 El-Hayek G, Bangalore S, Casso Dominguez A, et al. Meta-analysis of randomized clinical trials comparing biodegradable polymer drug-eluting stent to secondgeneration durable polymer drug-eluting stents. JACC Cardiovasc Interv 2017:10:462-73.

7 Sorrentino S, Giustino G, Mehran R, et al. Everolimus-eluting bioresorbable scaffolds versus everolimus-eluting metallic stents. J Am Coll Cardiol 2017:69:3055-66.

8 Chaitman BR, Davis KB, Dodge HT, et al. Should airline pilots be eligible to resume active flight status after coronary bypass surgery?: a CASS registry study. J Am Coll Cardiol 1986;8:1318-24.

9 Dargie HJ. First European workship in aviation cardiology. Late results following coronary artery bypass grafting. Eur Heart J;1992:13(suppl H):89-95.

10 Chua TP, Sigwart U. Second European workship in aviation cardiology. What is acceptable revascularization of the myocardium in the context of certification to fly? Eur Heart J 1999:1:D78-83.

11 Mohr FW, Morice MC, Kappetein AP, et al. Coronary artery bypass graft surgery versus percutaneous coronary intervention in patients with three-vessel disease and left main coronary disease: 5 -year follow-up of the randomised, clinical SYNTAX trial. Lancet 2013;381:629-38.

12 Buxton BF, Hayward PA, Newcomb AE, et al. Choice of conduits for coronary artery bypass grafting: craft or science? Eur J Cardiothorac Surg 2009;35:658-70.

13 Kieser TM, Head SJ, Kappetein AP. Arterial grafting and complete revascularization: challenge or compromise? Curr Opin Cardiol 2013;28:646-53.

14 Gaudino M, Niccoli G, Roberto M, et al. The same angiographic factors predict venous and arterial graft patency: a retrospective study. Medicine 2016;95:e2068.

15 Nakajima H, Kobayashi J, Toda K, et al. Angiographic evaluation of flow distribution in sequential and composite arterial grafts for three vessel disease. Eur J Cardiothorac Surg 2012;41:763-9.

16 Nakajima H, Kobayashi J, Toda K, et al. A 10-year angiographic follow-up of competitive flow in sequential and composite arterial grafts. Eur I Cardiothorac Surg 2011:40:399-404.

17 Nordgaard H, Swillens A, Nordhaug D, et al. Impact of competitive flow on wall shear stress in coronary surgery: computational fluid dynamics of a LIMA-LAD model. Cardiovasc Res 2010;88:512-9.

18 Park SJ, Ahn JM, Kim YH, et al. Trial of everolimus-eluting stents or bypass surgery for coronary disease. N Engl J Med 2015;372:1204-12.

19 Patel MR, Calhoon JH, Dehmer GJ, et al. ACC/AATS/AHA/ASE/ASNC/SCAI/SCCT/STS 2017 appropriate use criteria for coronary revascularization in patients with stable ischemic heart disease. J Am Coll Cardiol 2017;69:2212-41.

20 Montalescot G, Dallongeville J, Van Belle E, et al. STEMI and NSTEMI: are they so different? 1 year outcomes in acute myocardial infarction as defined by the ESC/ACC definition (the OPERA registry). Eur Heart J 2007:28:1409-17.

21 Bachinsky WB, Abdelsalam M, Boga G, et al. Comparative study of same sitting hybrid coronary artery revascularization versus off-pump coronary artery bypass in multivessel coronary artery disease. J Interv Cardiol 2012;25:460-8.

22 Halkos ME, Vassiliades TA, Douglas JS, et al. Hybrid coronary revascularization versus off-pump coronary artery bypass grafting for the treatment of multivessel coronary artery disease. Ann Thorac Surg 2011:92:1695-702.

23 Barnett SL, Fitzsimmons PJ, Kruyer WB. Coronary artery revascularization in aviators: outcomes in 122 former military aviators. Aviat Space Environ Med 2003; $74: 389$

24 Buffet P, Colasante B, Feldmann L, et al. Long-term follow-up after coronary angioplasty in patients younger than 40 years of age. Am Heart 1994;127:509-13.

25 Mehan VK, Urban P, Dorsaz PA, et al. Coronary angioplasty in the young: procedural results and late outcome. J Invasive Cardiol 1994;6:202-8.

26 Lytle BW, Kramer JR, Golding LR, et al. Young adults with coronary atherosclerosis: 10 year results of surgical myocardial revascularization. J Am Coll Cardiol 1984:4:445-53.

27 Lee PH, Lee SW, Yun SC, et al. Full metal jacket with drug-eluting stents for coronary chronic total occlusion. JACC Cardiovasc Interv 2017;10:1405-12.

28 HundleyWG, Bluemke DA, Finn JP, et al. ACCF/ACR/AHA/NASCI/SCMR 2010 expert consensus document on cardiovascular magnetic resonance. J Am Coll Cardiol 2010:55:2614-62
29 Roe MT, Messenger JC, Weintraub WS, et al. Treatments, trends, and outcomes of acute myocardial infarction and percutaneous coronary intervention. J Am Coll Cardiol 2010;56:254-63.

30 Puymirat E, Simon T, Steg PG, et al. Association of changes in clinical characteristics and management with improvement in survival among patients with ST-elevation myocardial infarction. JAMA 2012;308:998-1006.

31 Armstrong PW, Fu Y, Chang WC, et al. Acute coronary syndromes in the GUSTOIlb trial: prognostic insights and impact of recurrent ischemia. The GUSTO-IIb Investigators. Circulation 1998;98:1860-8.

32 Kastrati A, Neumann FJ, Schulz S, et al. Abciximab and heparin versus bivalirudin for non-ST-elevation myocardial infarction. N Engl J Med 2011;365:1980-9.

33 Bata IR, Gregor RD, Wolf HK, et al. Trends in five-year survival of patients discharged after acute myocardial infarction. Can J Cardiol 2006:22:399-404.

34 Stone GW, Witzenbichler B, Guagliumi G, et al. Heparin plus a glycoprotein IIb/IIla inhibitor versus bivalirudin monotherapy and paclitaxel-eluting stents versus baremetal stents in acute myocardial infarction (HORIZONS-AMI): final 3-year results from a multicentre, randomised controlled trial. Lancet 2011:377:2193-204.

35 Cole JH, Miller Jl, Sperling LS, et al. Long-term follow-up of coronary artery disease presenting in young adults. J Am Coll Cardiol 2003;41:521-8.

36 Moccetti T, Malacrida R, Pasotti E, et al. Epidemiologic variables and outcome of 1972 young patients with acute myocardial infarction. Data from the GISSI-2 database. Investigators of the Gruppo Italiano per lo Studio della Sopravvivenza nell'Infarto Miocardico (GISSI-2). Arch Intern Med 1997;157:865-9.

37 Füllhaas JU, Rickenbacher P, Pfisterer M, et al. Long-term prognosis of young patients after myocardial infarction in the thrombolytic era. Clin Cardiol 1997;20:993-8.

38 Batalla A, Reguero JR, Martín M, et al. Prognosis of coronary artery disease in young adults. Int J Cardiol 2004;97:327.

39 Lopes NH, Paulitsch FS, Gois AF, et al. Impact of number of vessels disease on outcome of patients with stable coronary artery disease: 5 -year follow-up of the Medical, Angioplasty, and bypass Surgery study (MASS). Eur I Cardiothorac Surg 2008;33:349-54.

40 Bhatt DL. Timely PCI for STEMI--still the treatment of choice. N Engl J Med 2013:368:1446-7.

41 Park DW, Clare RM, Schulte PJ, et al. Extent, location, and clinical significance of noninfarct-related coronary artery disease among patients with ST-elevation myocardial infarction. JAMA 2014;312:2019-27.

42 Gershlick AH, Khan JN, Kelly DJ, et al. Randomized trial of complete versus lesiononly revascularization in patients undergoing primary percutaneous coronary intervention for STEMI and multivessel disease: the CVLPRIT trial. J Am Coll Cardiol 2015;65:963-72.

43 Wald DS, Morris JK, Wald NJ, et al. Randomized trial of preventive angioplasty in myocardial infarction. N Eng/ J Med 2013;369:1115-23.

44 Davenport E, Gray G, Rienks R, et al. The management of established coronary artery disease in aircrew without infarction or revascularization. Heart 2018.

45 Smith SC, Benjamin EJ, Bonow RO, et al. AHA/ACCF secondary prevention and risk reduction therapy for patients with coronary and other atherosclerotic vascular disease: 2011 update: a guideline from the American Heart Association and American College of Cardiology Foundation. Circulation 2011;124:2458-73.

46 Eckel RH, Jakicic JM, Ard JD, et al. 2013 AHA/ACC guideline on lifestyle management to reduce cardiovascular risk: a report of the American College of Cardiology/ American Heart Association Task Force on Practice Guidelines. Circulation 2014;129:S76-99.

47 Perk J, De Backer G, Gohlke H, et al. European Guidelines on cardiovascular disease prevention in clinical practice (version 2012). The Fifth Joint Task Force of the European Society of Cardiology and Other Societies on Cardiovascular Disease Prevention in Clinical Practice (constituted by representatives of nine societies and by invited experts). Eur Heart J 2012;33:1635-701.

48 Sabatine MS, Giugliano RP, Keech AC, et al. Evolocumab and clinical outcomes in patients with cardiovascular disease. N Engl J Med Overseas Ed 2017:376:1713-22.

49 Metz LD, Beattie M, Hom R, et al. The prognostic value of normal exercise myocardial perfusion imaging and exercise echocardiography: a meta-analysis. J Am Coll Cardiol 2007; 49:227-37.

50 Chin AS, Goldman LE, Eisenberg MJ. Functional testing after coronary artery bypass graft surgery: a meta-analysis. Can J Cardiol 2003;19:802-8.

51 Dori G, Denekamp Y, Fishman S, et al. Exercise stress testing, myocardial perfusion imaging and stress echocardiography for detecting restenosis after successfu percutaneous transluminal coronary angioplasty: a review of performance. J Intern Med 2003:253:253-62. 